\title{
Interferon Regulatory Factor 1 (IRF-1) and IRF-2 Expression in Breast Cancer Tissue Microarrays
}

\author{
JUDITH M. CONNETT, ${ }^{1}$ LINDA BADRI, ${ }^{1}$ THOMAS J. GIORDANO,${ }^{2}$ WILLIAM C. CONNETT, ${ }^{3}$ \\ and GERARD M. DOHERTY ${ }^{1}$
}

\begin{abstract}
Interferon- $\gamma(\mathrm{IFN}-\gamma)$ is a pleiotropic cytokine with potent antitumor effects, both in vitro and in vivo. The antitumor activity of IFN- $\gamma$ is mediated in part through IFN regulatory factor-1 (IRF-1) and may be blocked by IRF-2. To test our hypothesis that some tumors escape the antitumor effects of IFN- $\gamma$ by cellular changes reflected in IRF-1 and IRF-2 expression, we examined IRF-1 and IRF-2 expression in tissue microarrays (TMA) containing 187 specimens of clinically defined invasive breast carcinoma. TMAs (Cooperative Breast Cancer Tissue Resource [CBCTR], National Cancer Institute [NCI]) were stained and then scored by three evaluators blinded to the patients' clinical status. After final scoring, the CBCTR provided the available clinical data for each patient. Whether sorted by carcinoma type or for all data together, statistical analysis showed a significant positive correlation between IRF-1 and IRF-2 expression $(p=0.01)$ and a negative correlation between IRF-1 expression and tumor grade $(p=0.005)$. IRF-1 expression is consistent with its role as a tumor suppressor; high-grade breast carcinomas were less likely to maintain expression of IRF-1, a finding consistent with a role for IRF-1 as a tumor suppressor. Further, tumors maintained expression of IRF-2 if there was coincident expression of IRF-1. These data support a model in which alterations of the expression of intracellular effectors of IFN- $\gamma$ signaling may diminish the immune-mediated tumor control mechanisms of IFN- $\gamma$.
\end{abstract}

\section{INTRODUCTION}

I NTERFERON- $\gamma($ IFN- $\gamma$ ) IS A PLEIOTROPIC cytokine that is produced by $\mathrm{T}$ lymphocytes and natural killer (NK) cells and has important roles in the systemic immune response. IFN- $\gamma$ upregulates MHC class I expression and induces MHC class II expression for antigen presentation. IFN- $\gamma$ also affects the monocyte/macrophage component of the immune system by inducing differentiation, promoting antigen presentation, and increasing expression of cell surface proteins that augment antigen presentation. Recently, IFN- $\gamma$ production by NK cells was demonstrated to upregulate TRAIL and Fas ligand (FasL) on these cells in an autocrine fashion, a necessary condition for NK killing of tumor cells in vivo. ${ }^{(1)}$

IFN- $\gamma$ has potent antitumor effects, both in vivo and in vitro. Our laboratory showed that endogenous IFN- $\gamma$ limits the in vivo growth of tumors in syngeneic mice and that blocking the endogenous IFN- $\gamma$ response using anti-IFN- $\gamma$ antibodies leads to an increase in tumor growth rate. ${ }^{(2,3)}$ This antitumor effect has been confirmed in syngeneic IFN- $\gamma$ knockout (IFN- $\gamma^{-1-}$ ) mice using B16-F10 murine melanoma. ${ }^{(4)}$ These tumor growth-inhibiting effects of IFN- $\gamma$ have been confirmed in other models. ${ }^{(1)}$ IFN regulatory factor-1 (IRF-1) is a major mediator of several observed effects of IFN- $\gamma$ on cells. ${ }^{(5-9)}$ IRF-1 binds to a specific sequence called the IFN response element (IRE) in the promoter region of inducible genes and causes upregulation of transcription. These genes include MHC I and II proteins, interleukin-4 (IL-4), IL-12, IL-15, IFN- $\alpha / \beta$, transporter associated with antigen processing-1 (TAP-1), cyclooxygenase-2 (Cox-2), p53, E-cadherin, lysyl oxidase, nitric oxide synthase (NOS), p21, gp91 ${ }^{\text {phox }}$, caspase 1 , caspase 7 , and potentially caspase $8 .^{(4,10-13)}$ Interestingly, there is an interaction of IRF-1 with IRF-2, another protein induced by IFN- $\gamma$ that binds the same DNA sequence as IRF-1. Unlike IRF-1, IRF-2 downregulates or blocks upregulation of gene transcription. ${ }^{(14)}$ IRF-2 is induced later than IRF-1 but seems to have greater protein stability (i.e., an 8-h half-life vs. a 30-min half-life for IRF-1). ${ }^{(14,15)}$ Therefore, IRF-2 may play a role in the feedback inhibition of 
the effects of IFN- $\gamma$ mediated by IRF-1. IRF-1 has been shown to slow cell growth and act as a tumor suppressor, whereas IRF2 seems to have oncogenic properties. ${ }^{(16)}$

In previous studies of human cancer cell lines and carcinoma tissues, we have established the following: (1) there is intercellular heterogeneity in the IRF-1 expression response to IFN- $\gamma$ in cell lines resistant to IFN- $\gamma$ compared with those sensitive to IFN$\gamma,{ }^{(17)}(2)$ in archival specimens of human melanoma, the loss of IRF-1 expression and gain of IRF-2 expression was associated with more advanced disease, including thicker primary tumors, nodular morphology, metastasis, and increasing American Joint Committee on Cancer (AJCC) stage, ${ }^{(18)}$ and (3) in a pilot study of archival human breast specimens, most normal breast tissue was found to express IRF-1 but not IRF-2. In contrast, IRF-1 expression decreased with tumor progression, whereas IRF-2 expression tended to increase with nuclear grade. ${ }^{(19)}$ Collectively, these studies suggest that IRF-1 acts as a tumor suppressor in inhibiting cell growth, whereas IRF-2 behaves as an oncogene in opposing the inhibition of IRF-1. The current hypothesis is that some tumors escape the endogenous IFN- $\gamma$ antitumor effects by changes in the response to IFN- $\gamma$, which may be reflected in IRF1 and IRF-2 expression. To test this hypothesis and to expand our recent limited study of IRF-1 and IRF-2 expression in archival human breast cancer tissues, we examined IRF-1 and IRF-2 expression in tissue microarrays (TMAs) containing 187 specimens of clinically defined invasive breast carcinoma. Although the tissue cores used in TMA studies are small compared with full sections, their effectiveness as tools in clinicopathologic studies has been rigorously validated in many studies. ${ }^{(20-23)}$

\section{MATERIALS AND METHODS}

\section{Antibodies}

Rabbit antihuman IRF-1 (G-20) and IRF-2 (C-19) antibodies (Abs) were from Santa Cruz (Santa Cruz, CA). Secondary goat antirabbit biotinylated horseradish peroxidase (HRP)-labeled Abs were from Vector (Burlingame, CA). The specificity of anti-IRF-1 was confirmed in immunohistochemical studies comparing breast tissue from normal C57B1/6 and IRF-1 knockout C57Bl/6 mice (Jackson Laboratory, Bar Harbor, ME). In these studies, both rabbit antimouse IRF-1 (M-20) and rabbit antihuman IRF-1 (G-20) Abs were used. Formalin-fixed tissues were sectioned onto glass slides and treated exactly for immunohistochemical evaluation. Previously, we had validated the specificity of both IRF-1 and IRF-2 Abs by electromobility shift assays (EMSA). ${ }^{(17,24)}$

\section{Tissue microarrays}

TMAs evaluated in these studies were obtained from the Cooperative Breast Cancer Tissue Resource (CBCTR) of the National Cancer Institute (NCI). The TMAs consisted of 288 0.6-mm cores taken from paraffin-embedded specimens representing 252 breast carcinomas and normal breast specimens plus 36 controls. Each array was created in duplicate to address possible tissue heterogeneity: two cores were taken from each specimen block, with one core per specimen appearing in each of the two replicate array blocks. The 252 normal breast and breast cancer cores appearing on each TMA block included (1) node- negative breast cancer: 64 samples, (2) node-positive breast cancer: 64 samples, (3) metastatic breast cancer: 64 samples, (4) ductal carcinoma in situ (DCIS): 20 samples (10 from individuals without an invasive disease component and 10 from individuals with invasive disease represented elsewhere on the TMA), and (5) normal breast tissue: 40 samples; 20 of these were from patients with invasive breast cancer, 10 were from patients with fibroadenoma, and 10 were from patients without cancer undergoing reduction mammoplasty. All of the invasive cases are primary invasive ductal carcinomas accessioned through the CBCTR. Thirty-six control cores are included on each TMA and represent 16 cores of normal nonbreast tissue and 20 cores of four cell lines.

\section{Whole tissue sections}

Twenty whole tissue sections of breast cancer from patients with samples included in the core TMA were obtained through coordinating efforts of the CBCTR. These were treated identically to the TMAs, and staining results for IRF-1 and IRF-2 were compared with core sample scores. Two of the whole tissue sections had damaged tissue and were not evaluated.

\section{Immunohistochemistry}

TMA slides were treated for antigen retrieval with a microwave oven, stained with appropriate antibodies, and detected with immunoperoxidase reagents (Vectastain kit, Vector, Burlingame, CA). After dewaxing and rehydration steps, slides were incubated in $0.01 \mathrm{M}$ citrate buffer $(\mathrm{pH}$ 6) for 4 min on high in a conventional microwave oven. Microwaving was interrupted every $15 \mathrm{sec}$ to rotate the Coplin jars, to agitate the solution, and to replace any buffer lost to boiling. After microwaving, slides were rinsed three times in phosphate-buffered saline (PBS), pH 7.4. Samples were quenched for endogenous peroxidase activity and stained according to the Vectastain kit. ${ }^{(25)}$ Slides were incubated with primary antibody (1:50 dilution) for $1 \mathrm{~h}$ and with secondary antibody for $30 \mathrm{~min}$ before rinsing and developing the peroxidase stain.

\section{Scoring}

Sections were scored by three evaluators, including a surgical pathologist (T.J.G.) blinded to the patient's clinical status. Breast carcinomas were given scores ranging from 0 to 3 based on the intensity of staining of the tumor cells. Any discrepancies among the scores of the evaluators were settled by reexaming together the tissues in question using a multihead microscope in the pathology department. Tissues thought to be in situ carcinoma were excluded from scoring. Results were sent to the CBCTR after collating all scores. The CBCTR then provided us with available clinical data, including type of disease, race, age, grade, stage, number of positive nodes, size of invasive cancer, and estrogen and progesterone receptor (ER and PR) status. Because each tumor was represented by two core samples, the final tumor staining score was the sum of both cores. Thus, the range of scores possible was 0-6.

\section{Statistics}

Patterns of IRF-1 and IRF-2 expression with cancer type, grade, stage, race, patient age, tumor size, number of lymph 


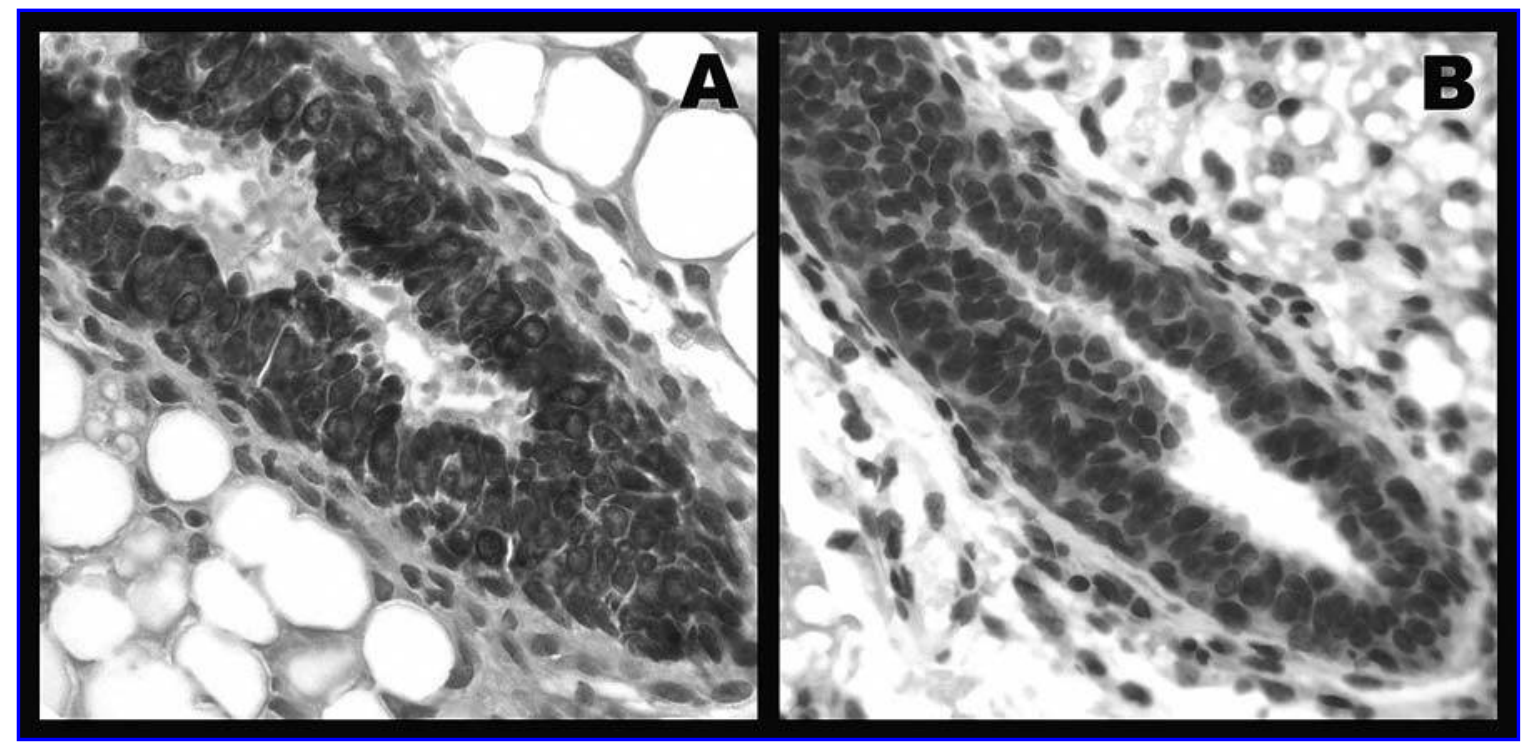

FIG. 1. Specificity of anti-IRF-1 antibody. Breast tissue from C57B1/6 wild-type mice (A) and from C57B1/6 IRF-1 knockout mice $(\mathbf{B})$ were stained with rabbit anti-IRF-1 Ab $(1 \mu \mathrm{g} / \mathrm{ml})$ as described. These histology pictures are representative of the results obtained on all the breast and intestinal tissues examined. Strong IRF-1 staining was seen in all wild-type tissue examined but not in tissue from the IRF-1 knockout mice.

nodes with tumor involvement, and estrogen and progesterone expression were analyzed using contingency tables and the Pearson chi-square statistic. Differences in levels of IRF-1 and IRF-2 expression with the variables were analyzed using the Wilcoxon (for two levels) and Kruskal-Wallace (for more than two levels) tests. Correlations among the experimental variables were analyzed using the Pearson correlation coefficient and Kendall's tau-b correlation coefficient. A result with $p \leq 0.05$ was considered significant. All calculations were performed using SAS (SAS Institute, Carey, NC).

\section{RESULTS}

The specificity of the anti-IRF-1 Ab used in these studies was confirmed by testing it on breast tissues from C57B1/6 IRF1 knockout mice and parental $\mathrm{C} 57 \mathrm{Bl} / 6$ mice. Breast tissues isolated from normal $\mathrm{C} 57 \mathrm{~B} 1 / 6$ parental mice displayed intense staining, whereas the IRF-1 knockout mouse tissues had no staining (Fig. 1). This result was obtained with both antimouse IRF-1 and antihuman IRF-1 Abs, demonstrating that antihuman IRF-1 Ab recognize mouse IRF-1 protein. IRF-2 knockout mice were not available for these studies, but both Western assay and EMSA with IRF-1 and IRF-2 Abs showed specificity and reactivity with different molecular weight bands documenting that these Abs were not cross-reactive. ${ }^{(17,24)}$

Representative IRF-1-stained tissue was selected to illustrate one of each score ranging from 0 to 3 (Fig. 2). The same core sample stained for IRF-2 is also shown illustrating both the similar tissue patterns for identical core sections in serial sections and the diversity of staining patterns seen with the two Abs on the same tissue. For all core samples, immunoreactivity was de-

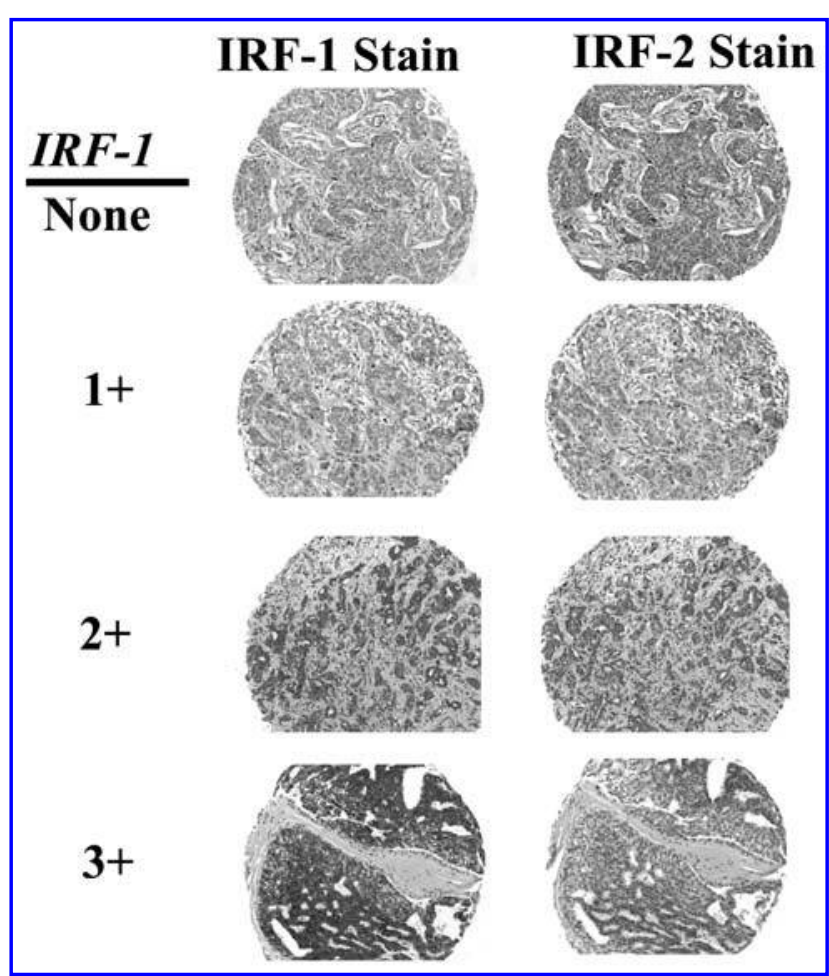

FIG. 2. Scoring system for antibodies. Core samples from 4 patients demonstrate the scoring system, which ranges from 0 to 3. A representative sample for each score is shown with the IRF-1 stain. The same core samples are shown after staining with IRF-2 and demonstrate the diversity of staining patterns between the two antibodies on the same tissue. 
pendent on the presence of the primary $\mathrm{Ab}$. We also compared the staining patterns of 18 whole tissue samples with core samples from the same patient (Fig. 3). This confirmed the validity of the TMA approach in our studies, as there was remarkable agreement in expression patterns for both IRF-1 and IRF-2 in core and whole tissue sections. The only exceptions were two whole tissue sections that were scored as negative for IRF2 staining and were scored as faintly positive in the core samples. Scoring results between the core samples and whole tissue sections showed 13 of 18 and 14 of 18 exact agreements for IRF-1 and IRF-2, respectively. Further, the few discordant scores were all within 1 of each other.
Statistical analyses were performed to uncover correlations between IRF-1 and IRF-2 expression with the clinical features of the patients and tumors (Table 1). In this study, all tumor samples expressed IRF-2 to some extent, and only 5 samples were negative for IRF-1 expression. IRF-1 expression was positively correlated with IRF-2 expression regardless of whether analysis included all data combined or data sorted by tumor metastasis status (Table 1). Importantly, IRF-1 expression was inversely correlated with tumor grade, confirming our earlier studies (Table 1 and Fig. 4). This result was found consistently across subsets of invasive cancer patients. The number of samples with strong IRF-1 staining decreased as tumors progressed

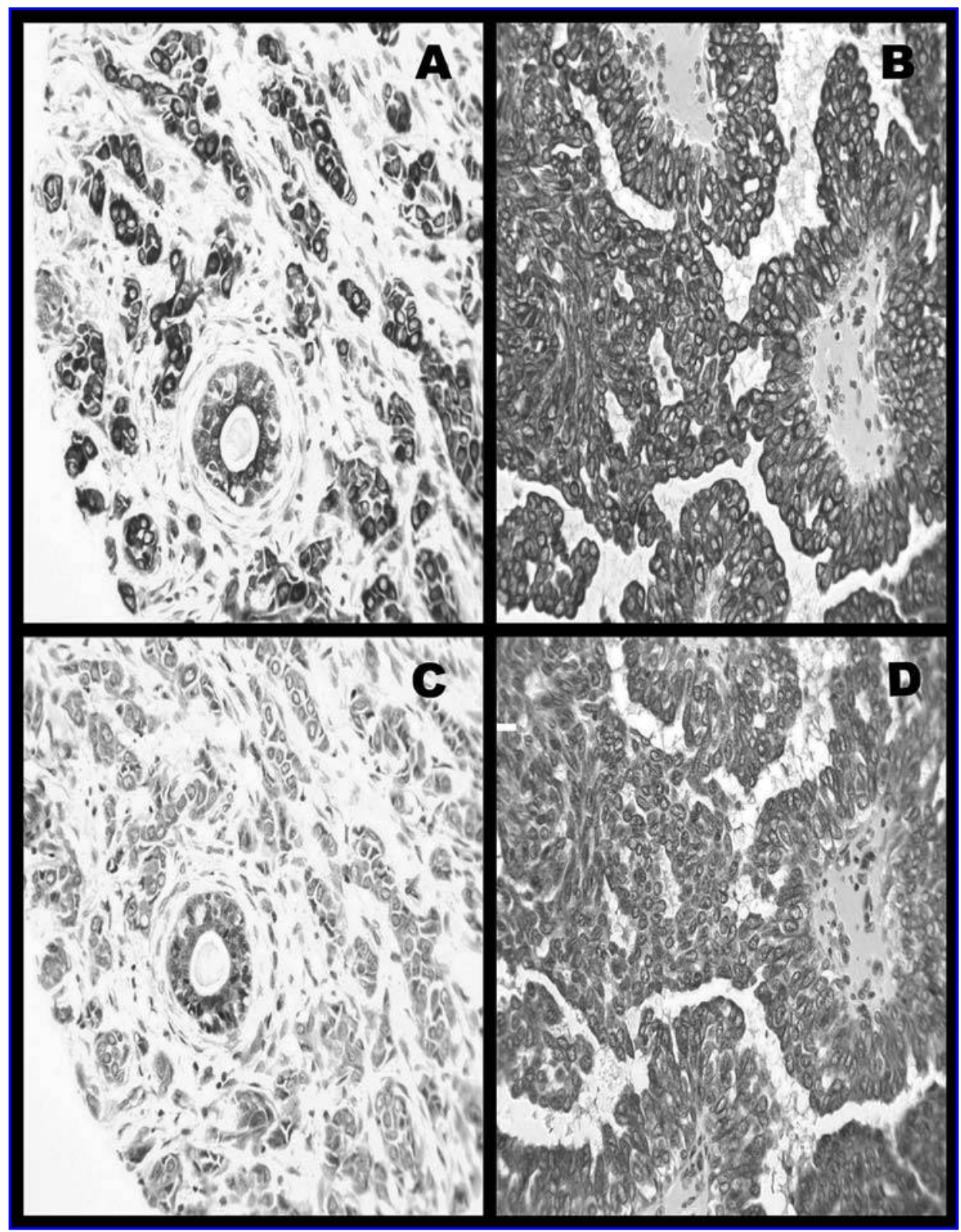

FIG. 3. Comparison of staining patterns of core tissue with whole tissue sections from the same patient. Core tissues from patient X stained with anti-IRF-1 and IRF-2 antibodies (A and $\mathbf{C}$, respectively). Whole tissue sections from patient X stained with anti-IRF-1 and IRF-2 antibodies (B and $\mathbf{D}$, respectively). In all, 18 patient samples comparing whole tissue sections with core tissue showed remarkable agreement in IRF-1 and IRF-2 expression patterns. 
Table 1. Tissue Microarray Statistical Results ${ }^{\mathrm{a}}$

\begin{tabular}{|c|c|c|c|c|c|}
\hline \multicolumn{3}{|c|}{ I. All data combined (no DCIS or normal tissue), $\mathrm{n}=187$} & \multicolumn{3}{|c|}{ III. Invasive node negative only, $\mathrm{n}=64$} \\
\hline Variables & Correlation $^{\mathrm{b}}$ & $\mathrm{p}$ value & Variables & Correlation $^{\mathrm{b}}$ & $\mathrm{p}$ value \\
\hline IRF-1 and IRF-2 & + & $<0.001$ & IRF-1 and IRF-2 & + & 0.0126 \\
\hline IRF-1 and age & + & 0.0148 & IRF-1 and size & - & 0.0794 \\
\hline IRF-1 and grade & - & $<0.001$ & IRF-1 and age & + & 0.0212 \\
\hline IRF-1 and size & - & 0.0825 & IRF-1 and grade & - & 0.0044 \\
\hline Size and age & - & 0.0686 & IRF-1 and stage & - & 0.0813 \\
\hline $\begin{array}{l}\text { Size and no. of nodes } \\
\text { positive }\end{array}$ & + & 0.0021 & Size and age & - & 0.0176 \\
\hline Size and grade & + & 0.0026 & Size and grade & + & 0.0012 \\
\hline Age and grade & - & 0.0012 & Size and stage & + & $<0.0001$ \\
\hline $\begin{array}{l}\text { No. of nodes positive } \\
\text { and stage }\end{array}$ & + & $<0.0001$ & Grade and age & - & $<0.0001$ \\
\hline Grade and stage & + & 0.0432 & Grade and stage & + & 0.0047 \\
\hline Size and stage & + & 0.0002 & & & \\
\hline \multicolumn{3}{|c|}{ II. Invasive distant mets only), $\mathrm{n}=63$} & \multicolumn{3}{|c|}{$I V$. Invasive node positive, $\mathrm{n}=60$} \\
\hline Variables & Correlation $^{\mathrm{b}}$ & $\mathrm{p}$ value & Variables & Correlation $^{\mathrm{b}}$ & $\mathrm{p}$ value \\
\hline IRF-1 and IRF-2 & + & 0.0001 & IRF-1 and IRF-2 & + & 0.0006 \\
\hline \multirow{3}{*}{ IRF-1 and grade } & - & 0.0833 & IRF-1 and grade & - & 0.0055 \\
\hline & & & $\begin{array}{l}\text { Size and no. of } \\
\text { positive }\end{array}$ & + & 0.0383 \\
\hline & & & $\begin{array}{l}\text { No. of nodes positive } \\
\text { positive }\end{array}$ & + & 0.0043 \\
\hline
\end{tabular}

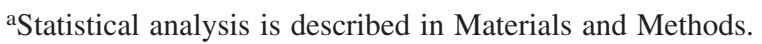

${ }^{\mathrm{b}} \mathrm{A}$ plus sign in the correlation column indicates a positive correlation of the two variables (e.g., as the number of tumor-positive nodes increases, so does tumor size increase), and a negative sign indicates an inverse correlation (e.g., IRF-1 expression is higher in small tumors and lower in bigger tumors).
}

from grade 1 to grade 3 (Fig. 4). No such correlation existed for IRF-2. When all the data were combined, IRF-1 expression was positively correlated with patient age and negatively correlated with tumor size. In the patients with node-negative invasive breast carcinoma, all the correlations held, and IRF-1 expression was also negatively correlated with tumor stage. In general, IRF-1 expression was somewhat higher in $\mathrm{ER}^{+}$than in $\mathrm{ER}^{-}$carcinomas (mean scores: $4.62 \pm 1.3$ and $3.52 \pm 1.8$, respectively; all data combined) $(p=0.0001)$. This trend was also observed in $\mathrm{PR}^{+}$vs. $\mathrm{PR}^{-}$carcinomas (mean scores: $4.58 \pm$ 1.4 and $3.81 \pm 1.7$, respectively) $(p=0.0015)$. In contrast, no significant differences existed in IRF-2 expression between $\mathrm{ER}^{+}(3.24 \pm 1.2)$ and $\mathrm{ER}^{-}(3.07 \pm 1.4)$ tumors or $\mathrm{PR}^{+}$ $(3.06 \pm 1.1)$ and $\mathrm{PR}^{-}(3.26 \pm 1.4)$ tumors. In fact, IRF-2 expression showed no significant correlations with any clinical parameter. The only positive correlation for IRF-2 expression was with IRF-1 expression.

The analysis also demonstrated positive and negative correlations between various clinical parameters known to be related, including a positive correlation between (1) number of tumorpositive lymph nodes and primary tumor size, (2) number of tumor-positive lymph nodes and grade, (3) tumor grade and tumor stage, (4) tumor size and stage, and (5) tumor size and grade and a negative correlation between (1) tumor size and patient age and (2) tumor grade and patient age. The correlation between IRF-1 and IRF-2 expression held across patient groups (Fig. 5). These data were sorted by IRF-1 score and plotted. Thus, for example, in Figure 5A, by looking at all the invasive cancer with metastases that had an IRF-1 score of 6 , one can see the variation in this group of patient samples in IRF-2 staining. As the IRF-1 expression increased, the IRF-2 expression also increased.

\section{DISCUSSION}

This is the first report of IRF-1 and IRF-2 expression patterns among significant numbers of breast carcinoma specimens. These studies extend our previous observations and demonstrate the involvement of the IRF-1/IRF-2 signal transduction system in human breast cancer. IRF-1 expression is consistent with its known biologic function as a tumor suppressor, and IRF-2 expression correlates with its role opposing IRF-1 effects. These expression patterns may be useful in determining prognosis or likelihood of response to therapy or as targets for future treatment strategies.

The validity of the TMA approach and Ab-binding specificity form a solid basis for the interpretation of this study. The staining patterns of 18 whole tissue sections and their sister core samples in the TMA show excellent agreement; this further validates the use of these small core samples to explore these protein expression patterns. Importantly, the reactivity of the antiIRF-1 Ab in tissue from IRF-1 knockout mice establishes the immunohistochemical specificity of this $\mathrm{Ab}$. In addition, previous Western blot and EMSA studies showed that IRF-1 and IRF-2 Abs (identical to those used in these TMA experiments) 


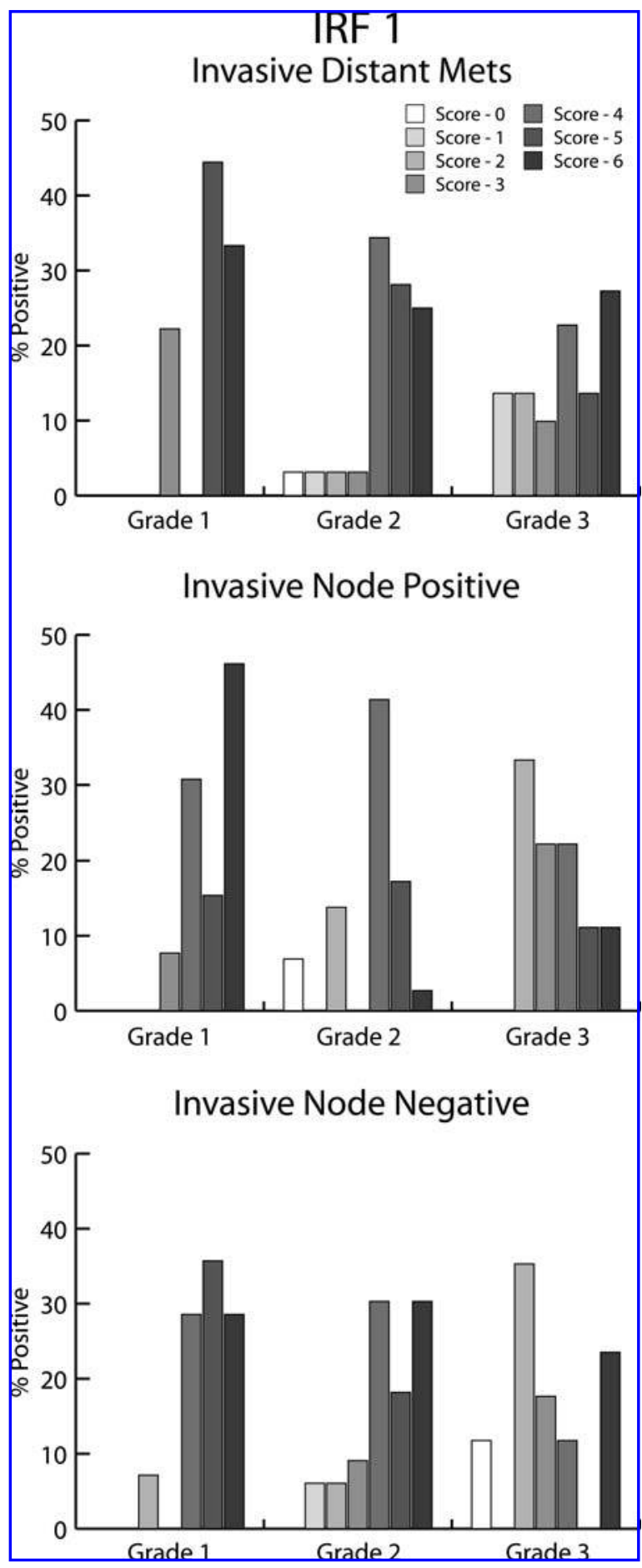

FIG. 4. Summary of staining patterns for IRF-1. Data are sorted by disease state and grade, and a histogram is constructed showing the percent of patients with each score. As each patient had two core samples tested with each antibody, these scores were added, accounting for the scoring range of 0-6. Mean scores \pm SD for each of the nine categories are shown above the grade. bind to discrete molecular weight bands. Also, immunohistochemistry expression of these proteins correlated with the Western blot and EMSA quantitation. ${ }^{(17,24)}$ Together, these results document both the specificity and noncross-reactivity of antiIRF-1 and anti-IRF-2 Abs. This is important, as the staining patterns but not the staining intensity of IRF-1 and IRF-2 were often very similar in serial sections.

This work is an expansion of our previous study on whole breast cancer and normal breast tissue sections. ${ }^{(19)}$ Underlying both studies is our hypothesis that IRF-1 expression in human tumors reflects the integrity of the IFN- $\gamma$ signal transduction pathway, and that this expression is correlated with a more favorable prognosis. We also evaluated IRF-2 expression patterns

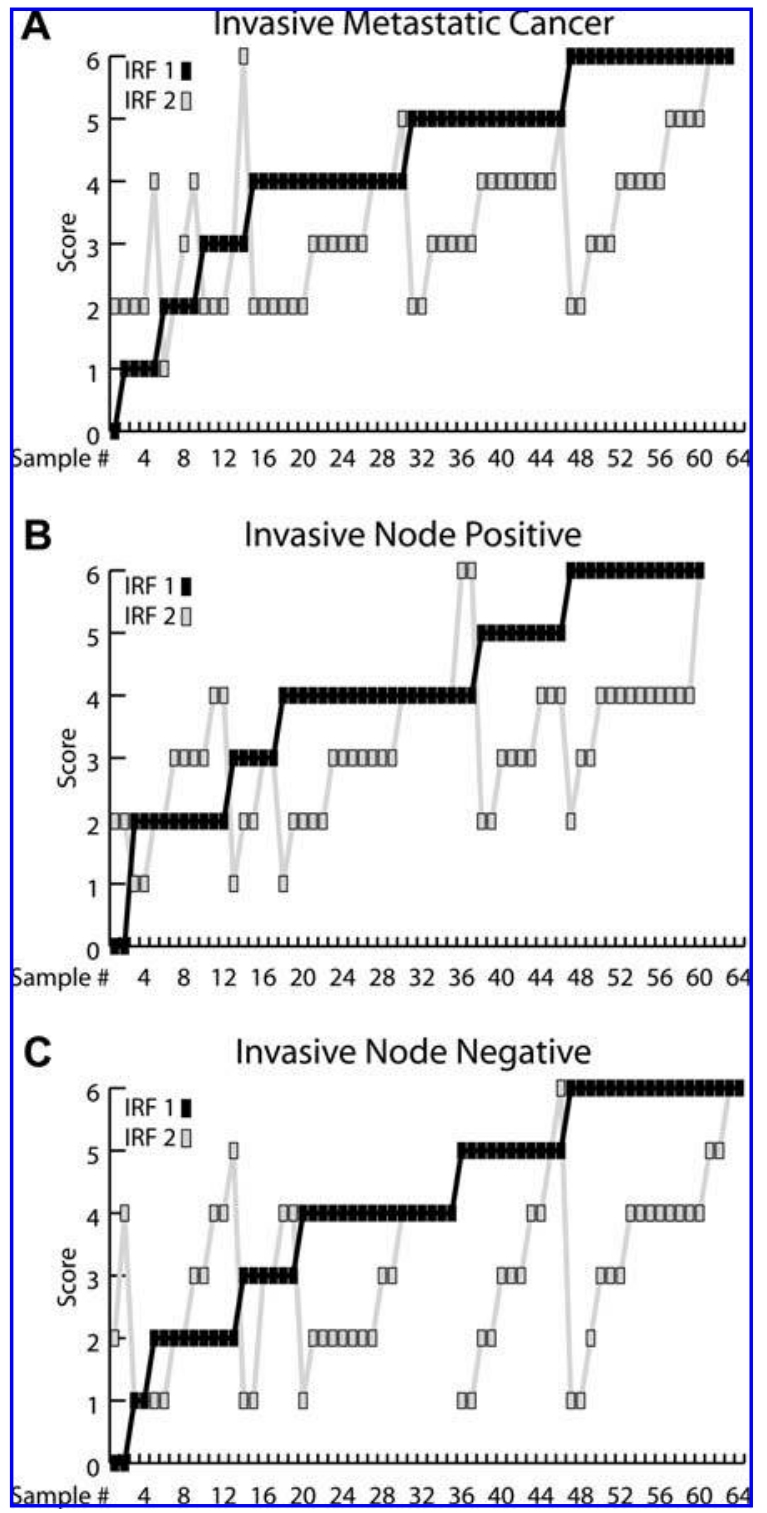

FIG. 5. (A, B, C) Expression patterns of IRF-1 and IRF-2. Within each disease state, data are sorted by IRF-1 score and plotted. For each patient sample, the corresponding IRF-2 score is shown. Thus, all the data on all the TMA slides are represented in this figure. 
because of its ability to act as an oncogene and to counter the tumor-suppressive effects of IRF-1. ${ }^{(18)}$ Although limited tissue supply precluded rigorous quantitative studies for IRF-1 and IRF-2 expression in TMA studies, our previous breast cancer study showed substantial differences in the frequency of IRF1 and IRF-2 expression between normal tissue and neoplastic breast tissues. These differences were consistent with the proposed roles of IRF-1 as a tumor suppressor and IRF-2 as an oncoprotein $^{(18)}$ and formed the basis for this current clinical translational study. Additionally, these studies showed that the loss of IRF-1 expression appeared to segregate with nuclear grade. Another of our previous studies evaluating IRF-1 and IRF-2 expression in human melanoma specimens also showed that IRF1 staining was correlated with less advanced disease. ${ }^{(18)} \mathrm{A}$ third study, by Kuroboshi et al., ${ }^{(26)}$ showed that IRF-1 expression in human uterine endometrial carcinoma was highest in normal endometrium and decreased with the grade of endometrial adenocarcinoma from grade 1 to grade 3 . Our present study confirms and extends the results of these three studies by showing that IRF-1 expression was inversely correlated with breast tumor grade. We also show that IRF-1 expression was negatively correlated with tumor size and positively correlated with patient age and that there was significantly more IRF-1 expression in $\mathrm{ER}^{+}$and $\mathrm{PR}^{+}$patients than in the population of $\mathrm{ER}^{-}$ and $\mathrm{PR}^{-}$patients. Whether the decrease in IRF-1 expression with advanced disease is a cause or a result of disease progression remains unclear.

The absence of any correlations with IRF-2 expression and clinical parameters may reflect the complexity by which IRF1 and IRF-2 compete to effect tumor suppression vs. tumor growth. Although many studies have established the antagonistic roles between IRF-1 and IRF-2 both in vitro and in vivo, the exact mechanism by which one or the other regulatory factor tips the balance in the tumor cell to either life or death has not been defined. In previous studies, we hypothesized that it is the ratio of IRF-1/IRF-2 expression that determines the outcome. ${ }^{(25)}$ In fact, the ratio of IRF-1/IRF-2 changes during the cell cycle, being at its highest in growth-arrested cells and at its lowest following growth stimulation. (27) Because this ratio is not directly measurable from these histology studies, our data cannot address this possibility. Other studies have suggested that posttranslational modifications are more important than the absolute amounts of IRF-1 and IRF-2 for activation of one or both regulatory factors. Acetylated IRF-2 can inhibit acetylation of core histones, thus repressing transcription of certain target genes and regulating cell growth. ${ }^{(28)}$ For instance, unacetylated IRF-2 could not effect this repression. In NIH 3T3 cells, levels of total IRF-2 were comparable in both growing and growth-arrested cells, but IRF-2 was acetylated only in growing cells. ${ }^{(29)}$ Other studies have shown that IRF-1 is phosphorylated in vivo, and dephosphorylation of IRF-1 in vitro causes a reduction in its DNA-binding activity. ${ }^{(30)}$ In addition, treatment of cells with the serine/threonine protein kinase inhibitor staurosporine causes a decrease in IRF-1-activated transcription. ${ }^{(31)}$ There is no agreement as to whether the amount of IRF1 , its phosphorylation, or a combination of the two is the controlling element. Although we have not addressed questions of posttranslational modifications in these studies, our results showing a decreased expression of IRF-1 with increased tumor grade suggest that the amount of IRF-1 expressed by breast tu- mor cells does contribute to the balance of tumor suppression vs. tumor progression.

In conclusion, this study establishes that IRF-1 expression is decreased in higher-grade breast cancer and that IRF-1 and IRF2 expressions are positively correlated. Subtle differences in IRF-1/IRF-2 ratios or posttranslational modification may determine the fate of a cancer cell. Further investigation is warranted to determine the utility of assessing these transcription factors to determine prognosis or select treatment options for breast cancer patients.

\section{ACKNOWLEDGEMENTS}

This work was supported by National Cancer Institute grant R29-CA 73846-01A1 (G.M.D.), Susan G. Komen Foundation grant BCRT0100372 (J.M.C.), and the Frank Foundation (J.M.C.). We thank Brian Saunders, M.D., and Eve Bingham for their careful reading of and constructive comments about the manuscript.

\section{REFERENCES}

1. Walker PR, Saas P, Dietrich PY. Role of Fas ligand (CD95L) in immune escape: the tumor cell strikes back. $\underline{\text { J. Immunol. }}$ 1997; 158:4521-4524.

2. Doherty GM, McCluskey B, Tsung K, Norton JA. Correlation of interferon regulatory factors 1 and 2 (IRF-1 and -2): expression and murine tumor growth in the presence of interferon-gamma. Surg. Forum 1995;46:544-546.

3. Doherty GM, Alexander HR, Merino MJ, Venzon DJ, Norton JA. Role of endogenous interferon gamma in murine tumor growth and tumor necrosis factor alpha antitumor efficacy. Ann. Surg. Oncol. 1996;3:198-203.

4. Yim JH, Wu S, Vander Velde TL, Norton JA, Doherty GM. Interferon regulatory factor-2 gene transfer into murine melanoma enhances tumorigenicity and resistance to interferon- $\gamma$ and tumor necrosis factor- $\alpha$. Proc. Am. Assoc. Cancer Res. 1997;38:96.

5. Fujita T, Reis LF, Watanabe N, Kimura Y, Taniguchi T, Vilcek J. Induction of the transcription factor IRF-1 and interferon-beta mRNAs by cytokines and activators of secondmessenger pathways. Proc. Natl. Acad. Sci. USA 1989;86: 9936-9940.

6. Geller DA, Nguyen D, Shapiro RA, Nussler A, Di Silvio M, Freeswick P, Wang SC, Tweardy DJ, Simmons RL, Billiar TR. Cytokine induction of interferon regulatory factor-1 in hepatocytes. Surgery 1993;114:235-242.

7. Harroch S, Revel M, Chebath J. Induction by interleukin-6 of interferon regulatory factor 1 (IRF-1) gene expression through the palindromic interferon response element pIRE and cell type-dependent control of IRF-1 binding to DNA. EMBO J. 1994;13: 1942-1949.

8. Martin E, Nathan C, Xie Q-W. Role of interferon regulatory factor 1 in induction of nitric oxide synthase. J. Exp. Med. 1994; 180:977-984.

9. Briken V, Ruffner H, Schultz U, Schwarz A, Reis LFL, Strehlow I, Decker T, Staeheli P. Interferon regulatory factor 1 is required for mouse Gbp gene activation by gamma interferon. $\underline{\text { Mol. Cell. }}$ Biol. 1995;15:975-982.

10. Taniguchi T, Ogasawara K, Takaoka A, Tanaka N. IRF family of transcription factors as regulators of host defense. Annu. Rev. Immunol. 2001;19:623-655. 
11. Chang C-H, Hammer J, Loh JE, Fodor WL, Flavell RA. The activation of major histocompatibility complex class I genes by interferon regulatory factor-1 (IRF-1). Immunogenetics 1992;35:378384.

12. Reis LFL, Harada H, Wolchok JD, Taniguchi T, Vilcek J. Critical role of a common transcription factor, IRF-1, in the regulation of IFN-beta and IFN-inducible genes. EMBO J. 1992;11:185-193.

13. Sok-Pin Tan R, Taniguchi T, Harada H. Identification of the lysyl oxidase gene as a target of the antioncogenic transcription factor, IRF-1, and its possible role in tumor suppression. Cancer Res. 1996;56:2417-2421.

14. Harada H, Kitagawa M, Tanaka N, Yamamoto H, Harada K, Ishihara M, Taniguchi T. Anti-oncogenic and oncogenic potentials of interferon regulatory factors-1 and -2. Science 1993;259:971-974.

15. Fujita T, Kimura Y, Miyamoto M, Barsoumian EL, Taniguchi T. Induction of endogenous IFN-alpha and IFN-beta genes by a regulatory transcription factor, IRF-1. Nature 1989;337:270-272.

16. Tanaka N, Kawakami T, Taniguchi T. Recognition DNA sequences of interferon regulatory factor 1 (IRF-1) and IRF-2, regulators of cell growth and the interferon system. Mol. Cell. Biol. 1993;13: $4531-4538$.

17. Connett JM, Hunt SR, Hickerson SM, Wu S, Doherty GM. Localization of IFN- $\gamma$-gamma-activated Stat 1 and interferon regulatory factors 1 and 2 in breast cancer cells. J. Interferon Cytokine Res. 2003;23:621-630.

18. Lowney JK, Boucher LD, Swanson PE, Doherty GM. Interferon regulatory factor-1 and -2 expression in human melanoma specimens. Ann. Surg. Oncol. 1999;6:604-608.

19. Doherty GM, Boucher L, Sorenson K, Lowney J. Interferon regulatory factor expression in human breast cancer. Ann. Surg. 2001;233:623-629.

20. Nocito A, Bubendorf L, Maria Tinner E, Suess K, Wagner U, Forster T, Kononen J, Fijan A, Bruderer J, Schmid U, Ackermann D, Maurer R, Alund G, Knonagel H, Rist M, Anabitarte M, Hering F, Hardmeier T, Schoenenberger AJ, Flury R, Jager P, Luc Fehr J, Schraml P, Moch H, Mihatsch MJ, Gasser T, Sauter G. Microarrays of bladder cancer tissue are highly representative of proliferation index and histological grade. J. Pathol. 2001;194:349-357.

21. Schraml P, Kononen J, Bubendorf L, Moch H, Bissig H, Nocito A, Mihatsch MJ, Kallioniemi OP, Sauter G. Tissue microarrays for gene amplification surveys in many different tumor types. Clin. Cancer Res. 1999;5:1966-1975.

22. Richter J, Wagner U, Kononen J, Fijan A, Bruderer J, Schmid U, Ackermann D, Maurer R, Alund G, Knonagel H, Rist M, Wilber K, Anabitarte M, Hering F, Hardmeier T, Schonenberger A, Flury R, Jager P, Fehr JL, Schraml P, Moch H, Mihatsch MJ, Gasser T, Kallioniemi OP, Sauter G. High-throughput tissue microarray analysis of cyclin E gene amplification and overexpression in urinary bladder cancer. Am. J. Pathol. 2000;157:787-794.
23. Callagy G, Cattaneo E, Daigo Y, Happerfield L, Bobrow LG, Pharoah PD, Caldas C. Molecular classification of breast carcinomas using tissue microarrays. Diagn. Mol. Pathol. 2003;12:27-34.

24. Yim JH, Connett JM, Ro SH, Lowney JK, Wu SJ, Doherty GM. The role of interferon regulatory factor- 1 and interferon regulatory factor- 2 in IFN- $\gamma$ growth inhibition of human breast carcinoma cell lines. J. Interferon Cytokine Res. 2003;23:501-511.

25. Yim J, Ro SH, Lowney JK, Wu SJ, Connett J, Doherty GM. The role of interferon regulatory factor- 1 and interferon regulatory factor-2 in IFN- $\gamma$ growth inhibition of human breast carcinoma cell lines. J. Interferon Cytokine Res. 2003;23:501-511.

26. Kuroboshi H, Okubo T, Kitaya K, Nakayama T, Daikoku N, Fushiki S, Honjo H. Interferon regulatory factor-1 expression in human uterine endometrial carcinoma. Gynecol. Oncol. 2003; 91354-358.

27. Coccia EM, Del Russo N, Stellacci E, Orsatti R, Benedetti E, Marziali G, Hiscott J, Battistini A. Activation and repression of the 2-5A synthetase and p21 gene promoters by IRF-1 and IRF-2. Oncogene 1999;18:2129-2137.

28. Masumi A, Ozato K. Coactivator p300 acetylates the interferon regulatory factor-2 in U937 cells following phorbol ester treatment. J. Biol. Chem. 2001;276:20973-20980.

29. Masumi A, Yamakawa Y, Fukazawa H, Ozato K, Komuro K. Interferon regulatory factor-2 regulates cell growth through its acetylation. J. Biol. Chem. 2003;278:25401-25407.

30. Pine R, Decker T, Kessler DS, Levy DE, Darnell JE, Jr. Purification and cloning of interferon-stimulated gene factor 2 (ISGF2): ISGF2 (IRF-1) can bind to the promoters of both beta interferonand interferon-stimulated genes but is not a primary transcriptional activator of either. Mol. Cell. Biol. 1990;10:2448-2457.

31. Watanabe N, Sakakibara J, Hovanessian AG, Taniguchi T, Fujita T. Activation of IFN-beta element by IRF-1 requires a post-translational event in addition to IRF-1 synthesis. Nucleic Acids Res. 1991;19:4421-4428.

Address reprint requests or correspondence to: Dr. Gerard M. Doherty Department of Surgery University of Michigan A560E MSRBII

1150 W. Medical Center Drive Ann Arbor, MI 48109-0654

Tel: (734) 615-4741

Fax: (734) 936-5830

E-mail: gerardd@umich.edu

Received 24 March 2005/Accepted 22 April 2005 
This article has been cited by:

1. Alain G. Zeimet, Daniel Reimer, Dominik Wolf, Heidi Fiegl, Nicole Concin, Annemarie Wiedemair, Anna M. Wolf, Holger Rumpold, Elisabeth Müller-Holzner, Christian Marth. 2009. Intratumoral interferon regulatory factor (IRF)-1 but not IRF-2 is of relevance in predicting patient outcome in ovarian cancer. International Journal of Cancer 124:10, 2353-2360. [CrossRef]

2. M. Frontini, M. Vijayakumar, A. Garvin, N. Clarke. 2009. A ChIP-chip approach reveals a novel role for transcription factor IRF1 in the DNA damage response. Nucleic Acids Research 37:4, 1073-1085. [CrossRef]

3. M. Koeppel, S. J. van Heeringen, L. Smeenk, A. C. Navis, E. M. Janssen-Megens, M. Lohrum. 2008. The novel p53 target gene IRF2BP2 participates in cell survival during the p53 stress response. Nucleic Acids Research 37:2, 322-335. [CrossRef]

4. Tomohiko Tamura, Hideyuki Yanai, David Savitsky, Tadatsugu Taniguchi. 2008. The IRF Family Transcription Factors in Immunity and Oncogenesis. Annual Review of Immunology 26:1, 535-584. [CrossRef] 